\title{
Effect propylene glycol as a quality improvers for Portland and Portland-limestone cements
}

\begin{abstract}
The performance of propylene glycol (PG) on the grindability, setting and hardening of Portland (OPC) and Portland-Limestone cements (PLC) was studied. Propylene glycol was added to OPC clinker with percentage ratios; $0,0.03,0.04$ and $0.05 \mathrm{wt} . \%$ of the OPC clinker. PLC was made by replacing 5 and $10 \mathrm{wt} \%$ of OPC with limestone. PG offers better grinding aid performance with higher Blaine areas. Besides, presence of PG shows higher water of consistency and lower initial and final setting times. The mechanical properties of mortar specimens made from OPC and PLC admixed with PG were improved especially in the first 7 days. This explained due to increase in the cement fineness which leads to an increase in the degree of cement hydration, as well as to improvement in the interfacial transition zone between the cement paste and sand particles, thus resulting in an enhancement in the strength. DTA and SEM results confirmed the improved properties achieved due to admixing OPC or PLC with PG.
\end{abstract}
Highlights
a. Propylene glycol was tested as quality improvers for mortar specimens made from OPC and PLC. b. Presence of PG improves the grindability index; reduce the water demand and
the initial and final setting times of both OPC and PLC mortar specimens.
c. Beside it enhances the mechanical properties especially in the early stages of hydration.

Keywords: limestone, propylene glycol, grindability index, setting, hardening
Volume 4 Issue I - 2019

\author{
Eisa E Hekal, Hashem FS, Abdel MWahab \\ Chemistry Department, Faculty of Science, Ain Shams \\ University, Egypt
} Correspondence: Hashem FS, Chemistry Department, Faculty
of Science,Ain Shams University, Cairo, Egypt,

Tel+0020I I I 7845995, Email f_s_hashem@ymail.com

Received: August 03, 2017| Published: January 25, 2019

\section{Introduction}

Cement production has been much increased all over the word since the early 1950 s, especially in developing countries. ${ }^{1}$ This industry is considered as a one of the top high energy consumption industries. ${ }^{2}$ A considerable part of this energy consumption is consumed during clinker grinding. During cement milling, the cement particles could coat the milling walls, seal the armor plating and agglomerate forming small plates which absorb the impact. Grinding aids in most cases are organic based compounds that are used to reduce the energy required for grinding the clinker into a given fineness which increases the efficiency of the cement mill. Grinding in generally are classified according to their structures into glycols, alkanol amines and phenol type compounds. ${ }^{3,4}$ In addition to increase the efficiency of cement mill, grinding aids could effects on the fresh cement paste properties and so they could improve the strength development of the setting concrete. Grinding aids that provides these "extra" properties are called quality improvers or the name performance enhancer as we also may like to use. ${ }^{5-7}$ Recently, different parameters were employed in order to study in the characterization of the performance of grinding aids. ${ }^{8-10}$ Effective GAs are those which have significant effects on physicochemical and mechanical properties of cement. Researchers and companies led to design an effective grinding aid based on an optimum combination of raw materials, some of which are obtained from byproducts of other industrial processes, providing an excellent cost advantage. ${ }^{11}$ Portland limestone cement (PLC) can be produced by mixing Portland cement and limestone or inter-grinding with Portland cement clinker. Limestone is also provided for more than 25 countries to use of between $1 \%$ and $5 \%$ in their Portland cements.
Many countries also allow up to 35\% replacement of Portland cement by limestone. Presence of limestone in the binding system determines the acceleration of the cement during the initial hydration, especially of the tricalcium silicate. ${ }^{12}$ Beside, limestone particles can fill the gaps between the clinker particles, reducing the water demand and densifying the structure of the hardened cement paste. ${ }^{13,14}$ When cements were dry blended with $5 \%$ limestone, the specific surface increased from 395 to $486 \mathrm{~m}^{2} / \mathrm{kg}$ and the $45 \mu \mathrm{m}$ residue decreased from $12.0 \%$ to $10.8 \% .{ }^{15}$ Permeability is also reduced by use of limestone, probably due a reduction in the connectivity of the pores rather than to their volume. The improvement of pore structure attributed to the nucleation effect of the fine particles of $\mathrm{CaCO}_{3}{ }^{16}{ }^{16}$ The object of this study is to evaluate the performance of propylene glycol (PG) as an sustainable quality improvers for OPC and PLC cements. The effect of addition of (PG) on the grindability setting times and the mechanical properties of OPC and OPC-limestone cement was also investigated. Microstructure and phase composition were studied.

\section{Experimental}

\section{Materials}

Industrial clinker used for the production of ordinary type I Portland cement (OPC-I, 42.5N). Limestone with $\mathrm{CaCO}_{3}$ content higher than $75 \%$ was used in our study. The chemical oxide composition of OPC clinker and lime stone theoretical phase ratios calculated by Bogue formulae are presented in Table 1. Propylene glycol provided from Aldrich-sigma was used as grinding aids. Commercial grinding aids (CG) were used as reference grinding aids used in market. 
Table I Chemical oxide composition of OPC and limestone

\begin{tabular}{lll}
\hline Oxides & Portland cement & Limestone \\
\hline $\mathrm{SiO}_{2}$ & 19.78 & 3.63 \\
$\mathrm{Al}_{2} \mathrm{O}_{3}$ & 4.55 & 0.4 \\
$\mathrm{Fe}_{2} \mathrm{O}_{3}$ & 3.28 & 0.25 \\
$\mathrm{CaO}$ & 61.84 & 50.1 \\
$\mathrm{MgO}$ & 1.91 & 0.96 \\
$\mathrm{SO}_{3}$ & 2.54 & 0.18 \\
$\mathrm{Cl}$ & 0.06 & 0.07 \\
$\mathrm{~K}_{2} \mathrm{O}$ & 0.21 & 0.03 \\
$\mathrm{Na}_{2} \mathrm{O}$ & 0.24 & 0.34 \\
$\mathrm{L.O} . \mathrm{I}$ & 4.1 & 42.4 \\
$\mathrm{Total}(\mathrm{sum})$ & $98.5 \mathrm{I}$ & 98.36 \\
\hline
\end{tabular}

\section{Preparation of dry mixes}

During the grinding of OPC clinker, the grinding aids are added with the ratios $0,0.03,0.04$ and 0.05 wt. $\%$ of the clinker. OPClimestone blended cement (PLC) are prepared by replacement 5 and $10 \mathrm{wt} . \%$ of OPC by limestone. Two percentage of the grinding aids are added to PLC, 0.03 and 0.04 wt.\%, during the grinding process. A constant $5 \%$ of gypsum by weight of clinker has been added to each cement mixture. To compare the grindability of the different dry mixes, all the dry mixes were grinded for 45 minutes and the Blain surface area was measured.

\section{Preparation of cement mortar specimens}

Standard mortar mixtures have been prepared by using OPC and PLC. Mortar mixtures with sand: cement: water ratios of 3:1:0.5 (by weight) were prepared using automatic mixer. Table 2 shows the mixes composition and their notation used in this study. The freshly prepared mortar was placed in stainless steel moulds $(40 \times 40 \times 160 \mathrm{~mm})$ in two approximately equal layers. Each layer was compacted and pressed until homogeneous specimen was obtained. The moulds were then vigorously vibrated (by a Jolting apparatus) for a few minutes to remove air bubbles and to give a better compaction of the mortar. The surface of the mortar was smoothed by the aid of thin edged trowel. Mortar specimens after molding were cured in a humidity chamber at about $100 \%$ relative humidity at constant temperature of $23 \pm 1{ }^{\circ} \mathrm{C}$ for 1day. After the first day, the specimens were demoulded and cured in tap water till the time of testing for compressive strength at 2,7,28 and 90days.

Table 2 Mix compositions (mass \%) and their notations

\begin{tabular}{lllll}
\hline MIX name & cement & limestone & PG & CG \\
\hline M0 & 100 & - & 0 & 0 \\
MPI & 100 & - & 0.03 & - \\
MP2 & 100 & - & 0.04 & - \\
MP3 & 100 & - & 0.05 & - \\
MC1 & 100 & - & - & 0.03 \\
MC2 & 100 & - & - & 0.04 \\
MC3 & 100 & - & - & 0.05 \\
\hline
\end{tabular}

\begin{tabular}{lllll}
\multicolumn{2}{l}{ Table Continued... } \\
\hline MIX name & cement & limestone & PG & CG \\
\hline L5 & 95 & 5 & - & - \\
LIO & 90 & 10 & - & - \\
L5PI & 95 & 5 & 0.03 & - \\
L5P2 & 95 & 5 & 0.04 & - \\
L5CI & 95 & 5 & - & 0.03 \\
L5C2 & 95 & 5 & - & 0.04 \\
LIOPI & 90 & 10 & 0.03 & - \\
LIOP2 & 90 & 10 & 0.04 & - \\
LI0CI & 90 & 10 & & 0.03 \\
LI0C2 & 90 & 10 & & 0.04 \\
\hline
\end{tabular}

\section{Techniques}

The effectiveness of PG and the commercial grinding aid (CG) on the grindability of OPC clinker or OPC-limestone blended cement was evaluated through measuring the grindability index (G.I.). This calculated by using equation 1 :

$$
G . I=\cdot \frac{(B S) \text { aids }}{(B S) \text { control }}
$$

Where: (BS) aids is the Blaine surface area for OPC clinker or OPClimestone blended cement in presence of definite concentration of the used grinding aid.

And: (BS) $)_{\text {control }}$ is the Blaine surface area for OPC clinker or OPClimestone blended cement in absence of grinding aid.

The standard water of consistency and setting times for each hardened cement pastes were determined according to ASTM C187 and C191 test methods respectively. ${ }^{17,}{ }^{18}$ A set of three mortar specimens were used for the determination of compressive strength as described by ASTM Specifications. ${ }^{19}$ This was accomplished using a "Ton-industrial machine" for maximum load of 60tons. The resulting crushed specimens were ground, and the hydration reaction was stopped by stirring about 10 grams of the ground sample with $100 \mathrm{ml}$ of a mixture of acetone and methanol (1:1 by volume) using a magnetic stirrer for at least one hour and then the solvent mixture was removed by decantation and filtration. Finally, the sample was dried at $80^{\circ} \mathrm{C}$ in the dryer overnight. To evaluate the effect of the grinding aids on the mechanical properties of hardened mortar pastes, the relative compressive strengths were calculated using equation 2 :

$$
(\mathrm{C} . \mathrm{S})_{\mathrm{rel}}=\frac{(C . S) G}{(C . S)} \times 100
$$

Where: (C.S $)_{\mathrm{G}}$ is the compressive strength of mortar specimens admixed with grinding aid (GA) after a certain period of hardening $\mathrm{t}$; and, (C.S.) is the compressive strength of mortar in absence of GA after the same hardening time. The phase compositions and microstructure of the formed hydrates are tested on the dried samples using differential thermal analysis (DTA) and Scanning electron microscope (SEM).

\section{Results and discussion}

\section{Blaine area and grindability index}

Table 3 shows the Blaine area and the grindability index (GI) values 
of the dry mixes prepared from OPC and OPC-limestone blended cement (PLC) in presence of different dosage of propylene glycol (PG) and commercial grinding aid (CG) after grinding for 45 minutes. For OPC mixes, presence of grinding aids shows higher values of Blaine areas than the control mix. Beside, PG offers better grinding aid performance than the commercial grinding aid (CG). Moreover, GI values for PG increase by increasing the dose of PG from 0.03 to 0.05 while the commercial grinding aid (CG) does not show an increase in values of GI after $0.04 \mathrm{dose}$. Cement particles possess positive and negative charges when it ground into smaller particles. These charges make agglomeration of the cement particles and they become easier to adhere on the ball mill surface. Propylene glycol (PG) absorbed on the cement particles and ball mill surface via the hydroxyl groups which neutralize these electrostatic surface charge. Besides, the alkyl part of PG shield the surface charge of cement particle which reduces the adhesive forces leading to prevention of aggregation of the powder and coating on balls mill. ${ }^{20}$ This make the ball mill getting the higher capability to produce finer particles. ${ }^{2}$ The increase in the GI values by increasing PG dose could be related to the monolayer coverage of the solid surface..$^{21,22}$ For commercial grinding aids (CG) the unchanged GI values after 0.04 dose is attributed to the formation of multimolecular layers on the solid surfaces at excessive dose. Multimolcular layers of GAs can lead to the formation of capillary forces that favor agglomeration. As indicated from the values of Blaine area, L5 and L10 mixed shows higher Blaine areas then P0 mix. Replacement of OPC by $10 \%$ limestone (mix L10) shows higher Blaine area than $5 \%$ replacement (mix L5). In general, limestone particles are softer than clinker particles. ${ }^{23}$ These soft limestone particles tend to stick to the surfaces of the mill and grinding balls. Adhesion of limestone particles on the surfaces of balls increases the fracture and grinding efficiency of the mill. The combination effect of blending OPC by limestone and presence of grinding aids results in an enhancement in grindability index (GI), show Table 3 the highest GI values recorded were 1.22 and 1.32 for L5P2 and L10P2 mixes respectively.

Table 3 Blaine area and the Grindability index $(\mathrm{Gl})$ of various mixes

\begin{tabular}{lll}
\hline Mix & Blaine area $\left(\mathrm{cm}^{2} / \mathbf{g}\right)$ & GI \\
\hline M0 & 4096 & $\mathrm{I}$ \\
MPI & 4348 & 1.06 \\
MP2 & 4427 & 1.08 \\
MP3 & 4465 & 1.09 \\
MCI & 4321 & 1.055 \\
MC2 & 4315 & 1.054 \\
MC3 & 4102 & 1.01 \\
L5 & 4448 & 1 \\
L10 & 4698 & 1 \\
L5PI & 4762 & 1.076 \\
L5P2 & 5012 & 1.127 \\
L5CI & 5714 & 1.22 \\
L5C2 & 6216 & 1.32 \\
LIOPI & 4705 & 1.05 \\
LIOP2 & 4805 & 1.08 \\
L10C1 & 5606 & 1.17 \\
L10C2 & 5656 & 1.21 \\
\hline
\end{tabular}

\section{Standard water of consistency}

Figure 1(A) shows the standard water of consistency of OPC pastes admixed with $0,0.03,0.04$ and 0.05 wt.\% grinding aids. Higher water: cement ratio for normal consistency are observed in OPC pastes containing grinding aids (CG and PG). This could be related to the increase in the cement fineness as a result of presence of grinding aids. Increasing the finesses of cement requires higher amounts of water for proper lubrication. ${ }^{2}$ PG shows higher water of consistency for OPC pastes compared to the commercial grinding aid (CG) Increasing the dose of PG in the OPC paste increases the standard water of consistency while this not observed for CG. L5 and L10 pastes showed lower standard water of consistency than M0 paste. The finesses and the smooth surface of the limestone particles reduce the friction between particles and, therefore, favor their mobility in pastes leading to higher fluidity. The "packaging" effect of particles leads also to the decrease of amount of water needed for a good workability of the system..$^{24}$ Presence of grinding aids (CG and $\mathrm{PG}$ ) in Portland- lime stone pastes leads to increase the standard water of consistency Figure 1(B).
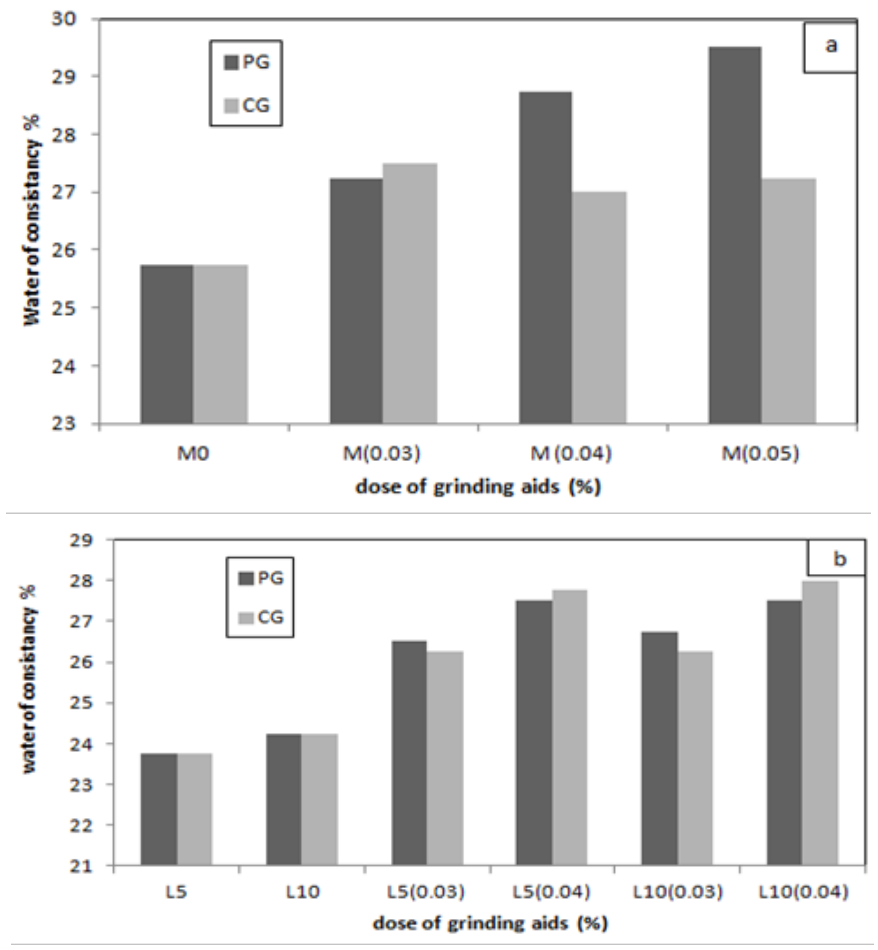

Figure I water of consistency of mixes admixed with various dose of propylene glycol (PG) and commercial grinding aids (MA).

(a) OPC mixes; (b) PLC mixes.

\section{Setting times}

Increasing the standard water of consistency in Portland cement pastes admixed with grinding aids leads to reduce the initial and final setting times, Figure 2(A). The initial and final setting times for Portland cement pastes admixed with propylene glycol were longer than those obtained for commercial grinding aid. This related to the increasing the finesses of the cement as a results of presence of grinding aids. This increases the initial rate of Portland cement hydration which fasts its hardness and stiffens. Blending of Portland cement by 5 and $10 \mathrm{wt} . \%$ limestone ( mixes L5 and L10 respectively) reduces both the initial and final setting times compared to neat 
M0 pastes. L5 paste shows shorter times for initial and final setting than L10 paste, Figure 2(B). This could be related to the nucleation effect formed by limestone particles inside the cement pastes which favorable the growth of the hydration products on it leading to acceleration of the hydration reaction. ${ }^{25}$ Again, presence of grinding aids in Portland- limestone pastes results in reducing of both initial and final setting times compared to L5 and L10 pastes, show Figure 2(B). This observed for propylene glycol and commercial grinding aids. The least setting time was recorded for L10P paste which showed a reduction by about $40 \%$ for both initial and final setting times compared to L10 paste.
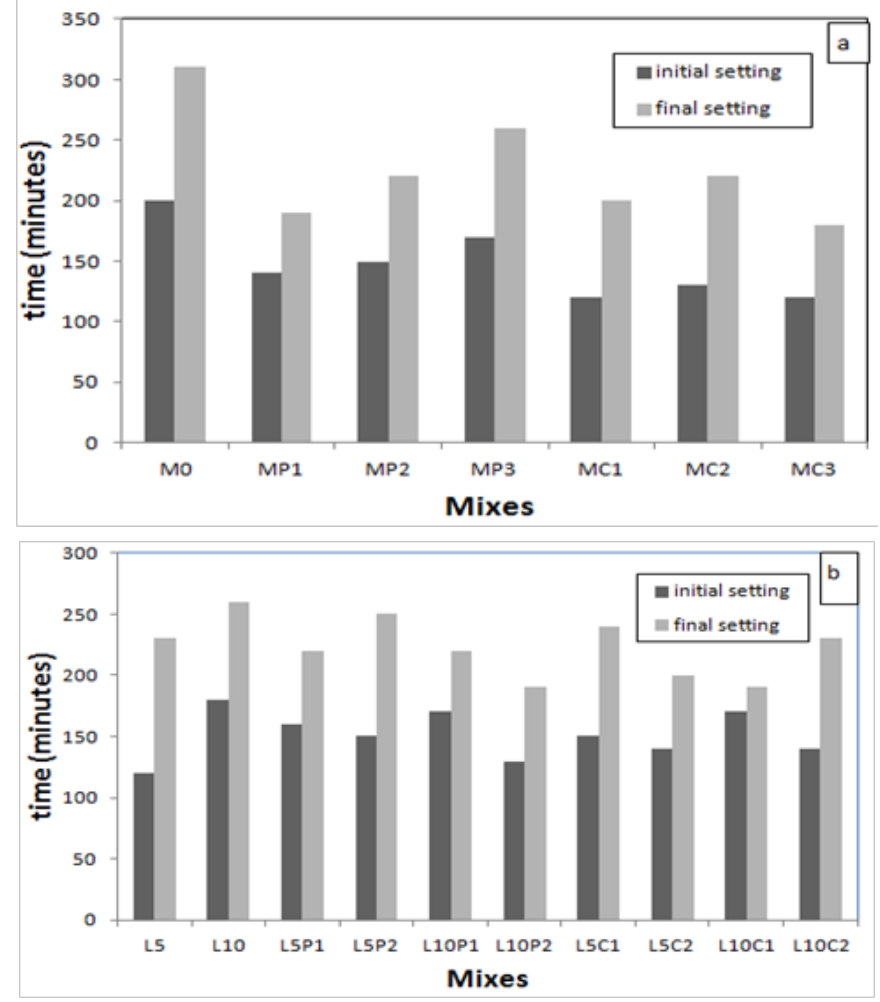

Figure 2 Setting times of PLC admixed with various dose of propylene glycol (PG) and commercial grinding aids (CG).

(a) OPC mixes; (b) PLC mixes.

\section{Compressive strength of mortar specimens}

The variation of the compressive strength values for mortar specimens made from OPC, sand and admixed with PG and commercial grinding aids after 2, 7, 28 and 90days are shown in Figure 3 \& Figure 4 respectively. The control mortar paste, M0, shows three stages of strength development with increasing the hydration ages up to 90days. A rapid increase in the compressive strength values is noticed during the first 7 days of hydration which represent the acceleration stage. This is followed by a continuous and gradual increase up to 28days. A slow increase in the compressive strength values noticed during the hydration period from 28 to 90 days. Mortar specimens admixed with propylene glycol or commercial grinding aid, showed the same trend of variation of compressive strength values with the hydration ages but with relatively higher values. The increase in the compressive strength values due to presence of grinding aids were evaluated via calculation of relative compressive strength which showed in Table 4. According to the values of the relative strength both the commercial grinding aid (M) and propylene glycol (PG) showed an increase in the relative strength values at all the hydration ages indicating the presence of the grinding aids causes an enhancement in the mechanical properties of hardened mortar. Moreover, the values of the relative strength increase with increasing the dose of the grinding aid which is more notable at early hydration ages, up to 7days, than the later ages. The improvement in relative strength due to presence of GAs may be attributed to increasing the cement fineness which leads to an increase in the degree of cement hydration, as well as to improvement in the interfacial transition zone between the cement paste and sand particles, thus resulting in increased strength. ${ }^{26}$ Jolicoeur et demonstrated that PG behave as accelerators for both silicates and aluminates phase and this accelerating effect of PG was mainly predominate at the early ages of the hydration. ${ }^{27}$ Figure 5 show the variation of the compressive strength values with the hydration ages for mortar specimens made from limestone cement (mixes PCL5 and PCL10 respectively). These mortar specimens showed lower values of the compressive strength than the mortar specimens made by OPC although the former showed higher Blaine areas and shorter setting times. This could be related to the dilution effect occurs via blending OPC by limestone and formation of calcium carbo-aluminate hydrates which have low mechanical properties. Admixing PCL mortars with 0.03 and 0.04 wt.\% propylene glycol or commercial grinding aids, mixes PGL and ML show an enhancement in the compressive strength values at all the hydration ages, Figure $6 \&$ Figure 7 respectively. This enhancement in the compressive strength values was more obvious at early hydration ages (at acceleration stages) and for mortar blended with 10\% limestone, mixes PGL10 and ML10, than 5\% limestone, mixes PGL5 and ML5. According to the values relative strength showed in Table 4, increasing the dose of PG from 0.03 to 0.04 wt.\% in all limestone blended cement has negative effect on the compressive strength value. While as, increasing the dose of commercial grinding aids (M) leads to increase the values of the compressive strength at all the hydration ages.

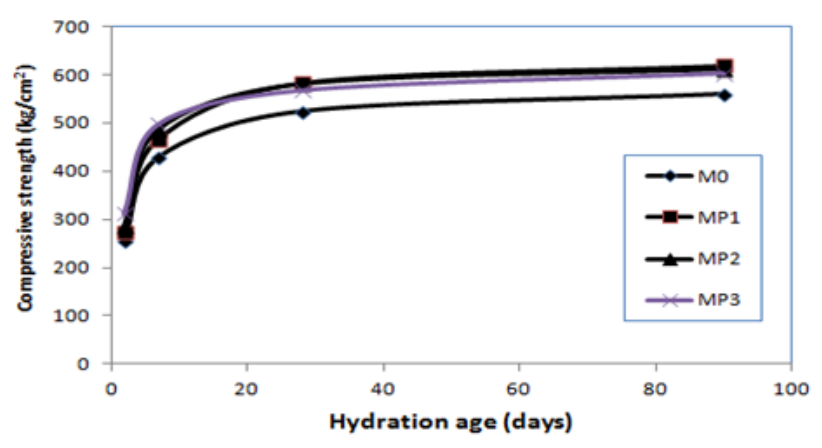

Figure 3 Compressive strength of OPC mortar admixed with propylene glycol at various hydration ages.

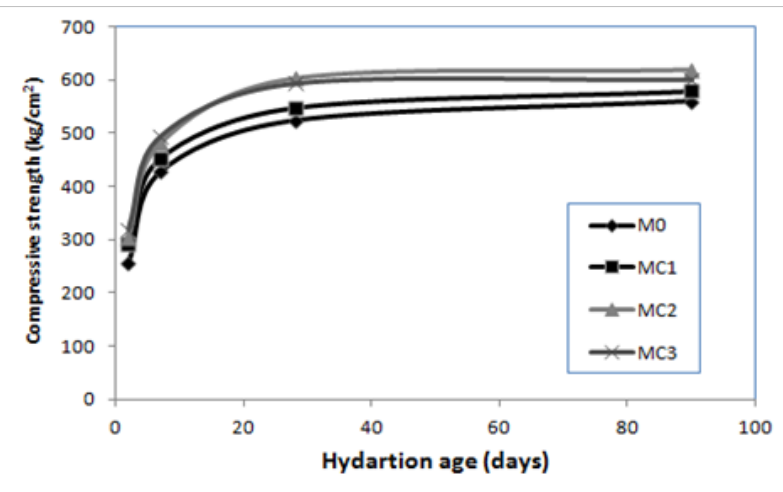

Figure 4 Compressive strength of OPC mortar admixed with commercial grinding aid at various hydration ages. 
Table 4 Relative compressive strength of different mixes

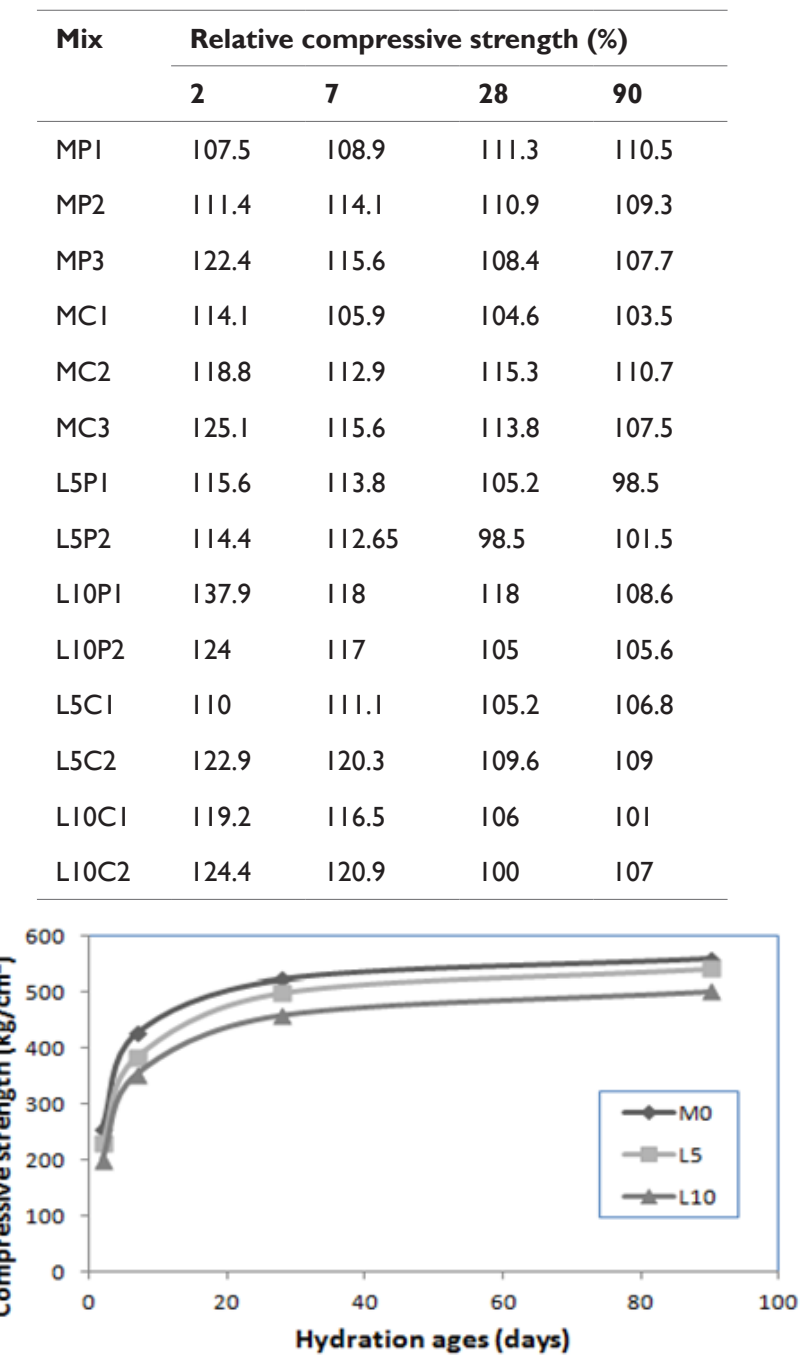

Figure 5 Compressive strength of PLC mortar at various hydration ages.

\section{Differential thermal analysis (DTA)}

DTA curves of the hardened mortar specimens made by $95 \%$ $\mathrm{OPC}+5 \%$ limestone and 95\% OPC $+5 \%$ limestone $+0.04 \% \mathrm{PG}$ , mixes L5 and L5P2 respectively after 2 and 90days of hydration are shown in Figure 7 \& Figure 8. L5 mix after 2days, see Figure 9(A), shows two endothermic peaks at $52^{\circ}, 106^{\circ} \mathrm{C}$ which are related to removal of free water and dehydration of amorphous and ill crystalline $\mathrm{CSH}^{28}$ Another endothermic peak is located at $465^{\circ} \mathrm{C}$, which is related to the dehydration of portalndite $(\mathrm{CH}) .{ }^{29}$ Three peaks are appeared $575^{\circ}, 677^{\circ}$ and $866^{\circ} \mathrm{C}$. These endotherms could be related to the decomposition of lime stone $\left(\mathrm{CaCO}_{3}\right)$ of varying degrees of crystallinity. ${ }^{30}$ After 90days, Figure 7(B), L5 mix shows the same endotherms in its DTA curve as after days but with a notable increase in the intensity of the peak characterized CSH which shifted to higher temperature and located at $136{ }^{\circ} \mathrm{C}$. This indicates intensive amounts with increased crystallinity of the hydration products are formed. DTA curve of mix LSP2 after 2days, see Figure 8(A), shows the same endotherms as L5 mix. The main difference was the slight increase in the enotherms characterized to $\mathrm{CSH}$ and $\mathrm{CH}$ located at $100^{\circ}$ and $462^{\circ} \mathrm{C}$ respectively. This confirms the compressive strength results that presence of PG enhances the hydration reaction leading to formation of more hydrates. After 90days, these two enotherms became more broadening and were shifted to higher temperatures; see Figure 8(B).
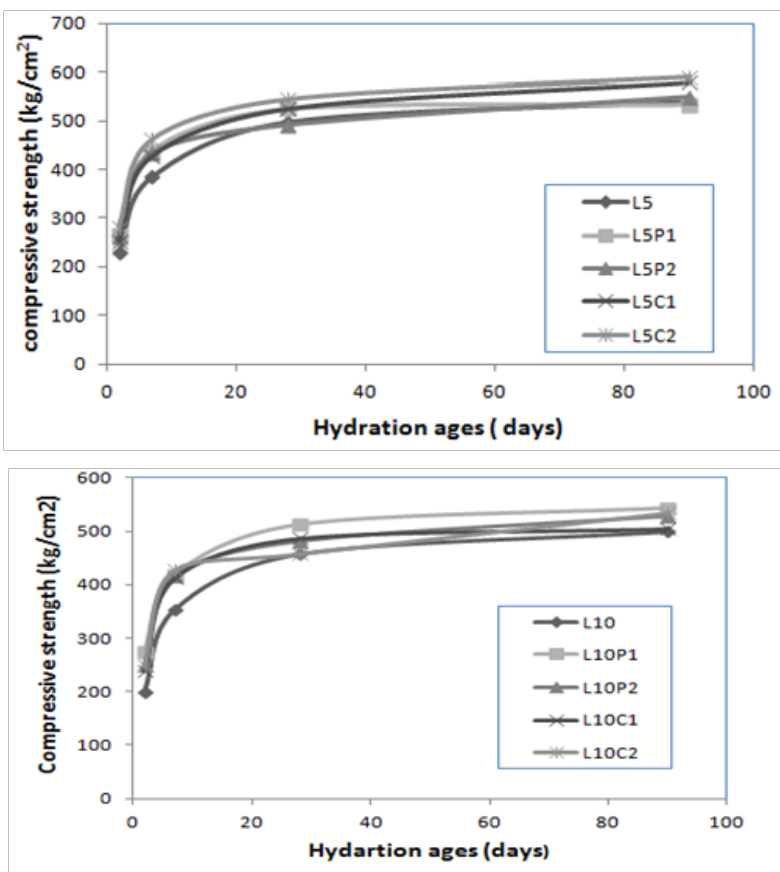

Figure 6 Compressive strength of PLC mortar admixed with grinding aids at various hydration ages

(a) mortar with $5 \%$ limestone; (b) mortar with $10 \%$ limestone.
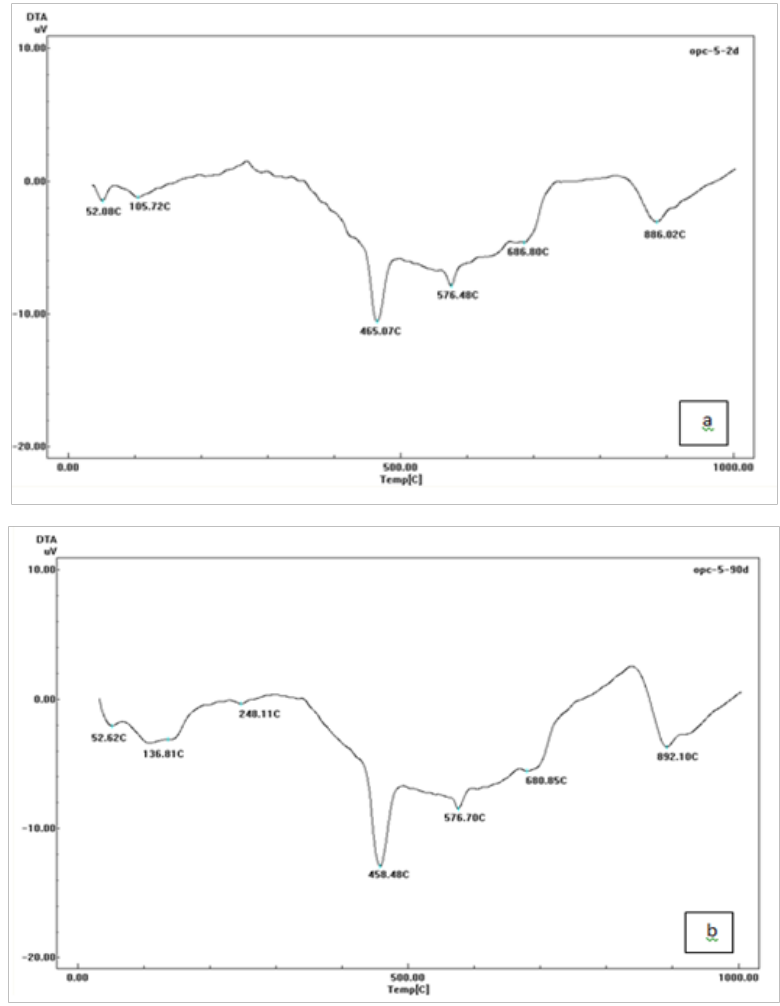

Figure 7 DTA curves of mortar specimens made from OPC- 5\%limestone mix L5.

after (a) days; (b) 90 days. 

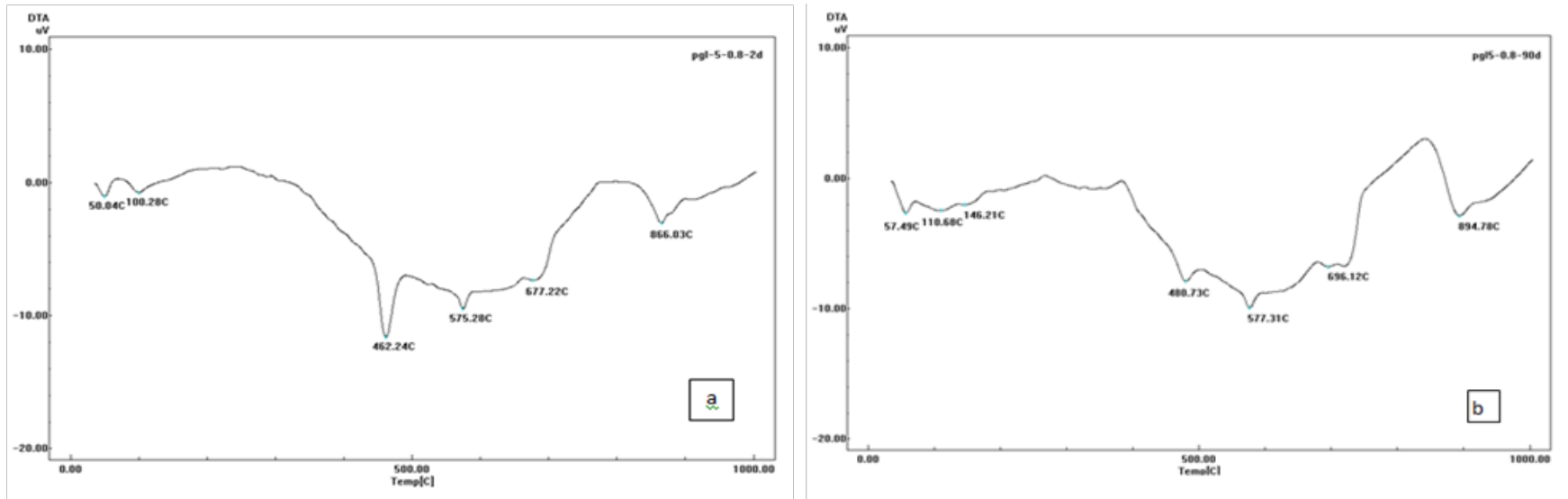

Figure 8 DTA curves of mortar specimens made from OPC- 5\% limestone and 0.04\%PG mix L5P2.

after (a) days; (b) 90 days.

\section{SEM}

Microstructure of the formed hydrates in $(95 \%$ OPC $+5 \%$ limestone) and (95\% OPC $+5 \%$ limestone $+0.04 \% \mathrm{PG})$, mixes L5 and L5P2 respectively after 90 days of hydration are shown in Figure 9. SEM micrograph of mix L5, Figure 9(A) displays the formation of both microcrystalline and fibrous crystals of cement hydration products, mainly as calcium silicate hydrates (CSH) with low porosities beside, crystals of calcium carbo-aluminate hydrates and limestone particle could be identified in SEM micrographs. For mix L5P2, SEM micrograph shows a more dense structure of the formed hydrates which represents the formation of almost nearly amorphous hydrates due to the low porosity and the limited pore volume available to the deposition of the formed hydrates, Figure 9(B) these types of amorphous and ill- crystallized hydrates lea to a hardened cement pastes with stronger hydraulic characteristics.
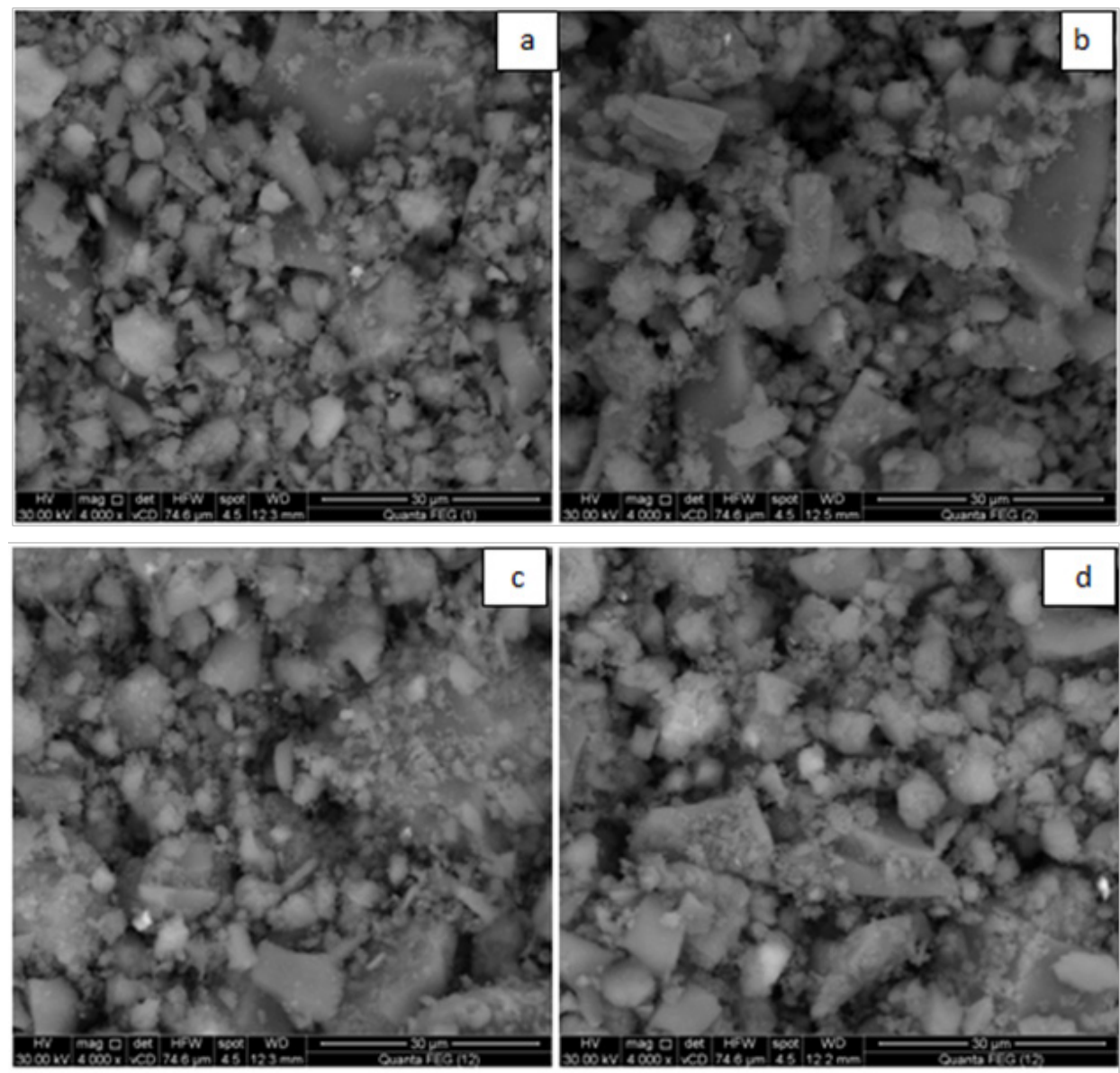

Figure 9 SEM micrographs of mortar mixes after 90 days of hydration.

(a) \& (b) mix L5; (c) \& (d) mix L5P2.

Citation: Hekal EE, Hashem FS, Wahab AM. Effect propylene glycol as a quality improvers for Portland and Portland-limestone cements. Int J Petrochem Sci Eng. 2019;4(I):I-7. DOI: 10.15406/ipcse.2019.04.00096 


\section{Conclusion}

On the basis of our study we can concluded that:

i. Admixing Portland clinker with Propylene glycol leads to increase its fineness.

ii. Replacing Portland cement clinker by 5 and $10 \%$ limestone leads to increase its Blaine area, as indicted by GI, this effect improved in the presence of Propylene glycol.

iii. Admixing of Portland and Portland-limestone cement by propylene glycol causes an increase in the water of consistency and reduction in both the initial and final setting times of their pastes.

iv. The mechanical properties of mortar specimens made from Portland and Portland-limestone cement admixed with PG were improved especially in the first 7 days.

v. DTA and SEM results confirmed the improved properties achieved due to admixing OPC or PLC with PG.

\section{Acknowledgments}

None.

\section{Conflicts of interest}

The authors declare that there are no conflicts of interest.

\section{References}

1. Heren Z, Ölmez H. The influence of ethanol amines on the hydration and mechanical properties of Portland cement. Cem Concr Res. 1996;26(5):701-705.

2. Assaad JJ, Asseily SE, Harb J. Use of cement grinding aids to optimize clinker factor. Adv Cem Res. 2009;22(1):29-36.

3. Heinz D, Gobel M, Hilbig H, et al. Effect of TEA on fly ash solubility at early age strength of mortar. Cem Conc Res. 2010;40(3):392-397.

4. Sandberg P, Doncaster F. On the mechanism of strength enhancement of cement paste and mortar with triisopropanol amine. Cem Conc Res. 2004;34(6);973-976.

5. Teoreanu I, Guslicov G. Mechanisms and effects of additives from the dihydroxy-compound class on Portland cement grinding. Cem Conc Res. 1999;29(1):9-15.

6. Katsioti M, Tsairidis PE, Giannatos P, et al. Characterization of various grinding aids and their impact on grindability and cement performance. Const Buil Mater. 2009;23(5):1954-1959.

7. Bravo A. Grinding aids: a study on their mechanism of action. ICCC Durban South Africa. 2003.

8. Gartner E, Myers D. Influence of tertiary Alkanol amines on Portland cement Hydration. J Amer Ceram Soc. 1993;76(6):305-319.

9. Teoreanu I, Guslicov G. Mechanisms and effects of additives from the dihydroxy-compound class on Portland cement grinding. Cem Conc Res. 1999;29(1):9-15.

10. Hasegawa M. The effect of liquid additives on dry ultrafine grinding of quartz. Powd Techn. 2001;114(1-3):145-151.
11. Fuerstenau DW, Abouzeid AMZ. The energy efficiency of ball milling in comminution. Inter J Miner Process. 2002;67(1-4):161-185.

12. Tsivilis S, Chaniotakis E, Kakali G. An Analysis of the Properties of Portland Limestone Cements and Concrete. Cem Concr Comp. 2002;24(3-4):371-378.

13. Siebel E, Sprung S. Influence of Limestone in Portland Limestone Cement on the Durability of Concrete. Beton. 1991;41(3):113-117.

14. Detwiler RJ. Properties of Concretes made with Fly Ash and Cements Containing Limestone, PCA R\&D Serial No. 2082. Portld Cem Associ. 1996.

15. Jackson PJ. Performance of Limestone-Filled Cements: Report of Joint BRE/BCA/Cement Industry Working Party, Building Research Establishment, Garston, Watford, England. 1989. 1993.

16. Chrici M, Kenai S, Mansour MS, et al. Mechanical properties and durability of mortar and concrete containing natural pazzolana and lime stone blended cement. Cem Concr Comp. 2007;29(7):542-549.

17. ASTM standards. Standard test method for normal consistency of hydraulic cement. ASTM C187-92:195. 2008.

18. ASTM standards. Standard test method for time of setting of hydraulic cement. Vicat needle, ASTM C191:208. 1983.

19. ASTM Designation: C-150. 2007.

20. Locher FW, Seebach HMV. Influence of Adsorption on Industrial Grinding. Industrial and Engineering Chemistry Process Des Dev. 1972;11(2):190-197.

21. Engelsen CH. Quality improvers in cement making-State of the art. COIN Project report no 2, SINTEF. 2008.

22. Teoreanu I, Guslicov G. Mechanisms and effects of additives from the dihydroxy-compound class on Portland cement grinding. $\mathrm{Cem} \mathrm{Concr}$ Res. 1999;29(1):9-15.

23. Erdoğdu K. Hydration Properties of Limestone Incorporated Cementitious Systems. 2002.

24. Voglis N, Kakali G, Chaniotakis E, Tsivilis S. Portland-limestone cements. Their properties and hydration compared to those of other composite cements. Cem Concr Comp. 2005;27(2):191-196.

25. Marzouki A, Lecomte A, Beddey A, et al. The effect of grinding on the properties of Portland-limestone cement. Const Build Mater. 2013;48:1145-1155.

26. Perez JP, Nonat A, Pourchet S, et al. Why TIPA leads to an increase in the mechanical properties of mortars whereas TEA does not. ACI Materials Journal. 2003;217:583-594.

27. Jolicoeur J, Morasse S, Shwrman J, et al. Polyol-type compounds as clinker grinding aids: influence of powder fluidity and on cement hydration. $12^{\text {th }}$ international Congress on the chemistry of cement. 2007.

28. Hashem FS, Amin MS, El-Gamal SMA. Improvement of acid resistance of Portland cement pastes using rice husk ash and cement kiln dust as additives. $J$ Therm Calorm. 2013;111:1391-1398.

29. Heikal M, El-Didamony H. Pozzolanic activity of Homra with lime. Mansoura Science Bulletin. 1999;7(3):154-159.

30. El-Gamal SMA, Hashem FS, Amin MS. Thermal resistance of hardened cement pastes containing vermiculite and expanded vermiculite. $J$ Therm Anal calorm. 2012;109(1):217-226. 